\title{
Pim1 Kinase Cooperates with Hormone Treatment to Promote Bladder and Ureteral Urothelial Hyperplasia
}

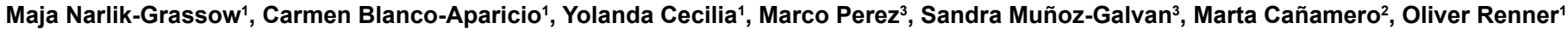
and Amancio Carnero ${ }^{3,4, *}$

${ }^{1}$ Experimental Therapeutics programme, Spanish National Cancer Research Centre (CNIO), Madrid, Spain

${ }^{2}$ Biotechnology programme, Spanish National Cancer Research Centre (CNIO), Madrid, Spain

${ }^{3}$ Instituto de Biomedicina de Sevilla (IBiS), HUVR/CSIC/Universidad de Sevilla, Sevilla, Spain

${ }^{4}$ Consejo Superior de Investigaciones Cientificas, Spain

\begin{abstract}
The Pim serine/threonine kinases have been shown to be overexpressed in cancer. Elevated levels of Pim1 kinase were demonstrated in human leukemia and lymphomas, as well as in solid tumors such as pancreatic, prostate and bladder cancers, and have been proposed as a prognostic marker. Although the Pim kinases have been identified as oncogenes in transgenic mouse models, they have only weak transforming abilities on their own. However, they have been shown to greatly enhance the ability of other genes or chemical carcinogens to induce tumors. To explore the role of Pim1 in bladder and ureteral urothelial cancer, we generated a conditional Pim1 transgenic mouse model and found that prostate specific antigen-(PSA)-driven Cre expression lead to transgene expression in the bladder upon (testosterone/estrogen) hormone treatment. We then explored the effect of Pim1 overexpression on hormone treatment, either alone or in combination with Pten haploinsufficiency. We found that Pim1 overexpression increased the severity of bladder and ureteral urothelial hyperplasias in both backgrounds, leading to pyelonephritis in transgenic animals. Our data suggest that Pim1 might contribute to progression, rather than initiation, and that the hyperplasias also contribute to the development of pyelonephritis.
\end{abstract}

Keywords: Pim1 kinase; Mouse models; Pyelonephritis; Urothelial hyperplasia

\section{Introduction}

The Pim proteins (Pim1, Pim2 and Pim3) are a family of short-lived serine/threonine kinases that are highly conserved in multicellular organisms. The different members are highly homologous at the amino acid level [1], but differ in their tissue distributions [2]. However, functional redundancy between the three Pim kinases has been shown in vitro $[3,4]$ and in vivo $[5,6]$.

Pim kinase transcription is rapidly upregulated in response to a wide range of growth factors [7-9], including interleukins and interferons. The majority of these factors transduce their primary signal through the JAK/STAT pathway [5]. Additionally, Pim1 is able to negatively regulate the JAK/STAT pathway by binding to SOCS proteins [10]. Gene expression of any of the 3 Pim kinases is also induced by activation of the NF- $\mathrm{kB}$ signaling pathway, hypoxia [11] and DNA damage, thereby protecting cells from apoptosis [12]. Pim kinases are not regulated by post-translational modifications like other kinases but are primarily regulated by transcription, translation, and proteosomal degradation [13-16].

Although the Pim kinases are only weakly transforming oncogenes, they have been shown to greatly enhance the ability of c-myc to induce lymphomas and prostate cancer [17-21], perhaps by counteracting Myc-induced apoptosis [22].

Pim kinases mediate their physiological activities through the phosphorylation of a wide range of cellular substrates, including cell cycle regulators such as $\mathrm{p} 21^{\text {wafl }}$ and $\mathrm{p} 27^{\text {kip1 }}[23,24]$, cdc25A [25] and cTAK/MARK3/Par1A; pro-apoptotic proteins such as Bad and ASK1 [26,27]; and transcriptional regulators such as RuNX1 and RuNX3 [28], HP1, NFATc1, c-Myb or p100 [29-33]. More recently, Pim2 has been shown to phosphorylate the ribosomal protein $4 \mathrm{E}-\mathrm{BP} 1$, affecting protein synthesis [34].
Elevated levels of Pim1 kinase were first reported in human leukemia and lymphomas $[8,35,36]$. Recently, Pim1 was found to be increased in solid tumors, including pancreatic, prostate and bladder cancers [37-40], as well as squamous cell carcinoma, gastric, colorectal and liver carcinomas [41,42], and liposarcoma [43]. Increased levels of Pim2 kinase have been detected in various lymphomas as well as in prostate cancer [44]. Pim3 kinase has been found to be aberrantly expressed in malignant lesions of endoderm-derived organs, such as the liver and pancreas, and in Ewing's sarcoma [1].

Bladder cancer $(\mathrm{BC})$ is one of the most common malignancies in the Western world. Approximately 3 out of 4 bladder tumors are diagnosed as non-invasive, with resection being the main therapy. However, the recurrence rate is very high $(50-70 \%)$, and on average $20 \%$ of non-invasive tumors progress to a muscle-invasive disease [ 45 47]. Therefore, the challenge for clinicians is the identification of novel therapeutic targets for bladder cancer chemotherapy. In this context, Pim1 has been shown to be overexpressed in BC epithelium, and the expression levels were higher in invasive bladder cancer than in noninvasive samples. Furthermore, Pim1 knockdown reduced bladder cancer cell growth and sensitized cells to chemotherapy in vitro [38].

We generated a conditional transgenic Pim1 mouse model that

*Corresponding author: Amancio Carnero, Instituto de Biomedicina de Sevilla (IBiS), Campus HUVR, Edificio IBIS. Avda. Manuel Siurot s/n. 41013, Sevilla, Spain, Tel: +34955923111; E-mail: acarnero-ibis@us.es

Received December 17, 2013; Accepted January 27, 2014; Published February 07,2014

Citation: Grassow MN, Aparicio CB, Cecilia Y, Perez M, Galvan SM, et al. (2014) Pim1 Kinase Cooperates with Hormone Treatment to Promote Bladder and Ureteral Urothelial Hyperplasia. J Carcinog Mutagen 5: 161. doi:10.4172/21572518.1000161

Copyright: (c) 2014 Grassow MN, et al. This is an open-access article distributed under the terms of the Creative Commons Attribution License, which permits unrestricted use, distribution, and reproduction in any medium, provided the original author and source are credited. 
surprisingly was able to show PSA-driven Cre expression under hormone treatment in urothelial cells. To further explore the role of Pim1 in bladder cancer initiation and progression, we used these conditional Pim1 transgenic mice that expressed Pim1 in urothelial cells upon hormone treatment, and analyzed the contribution of Pim1 hyperplasia and possible progression. Accordingly, we explored the effect of Pim1 overexpression upon hormone treatment, either alone or in combination with Pten haploinsufficiency.

\section{Methods}

\section{Construction of the transgenic DNA}

Human Pim1 gene was amplified by PCR using cDNA from human IMR90 cells as a template, with a Myc-tag being added via PCR. Human Pim1 was then cloned into the pVL-1 vector (Figure 1A). The DNA construct was injected into embryonic stem cells and proceed as indicated in [48]. Primers specifically designed for human Pim1 kinase, which do not amplify mouse Pim genes, were used for all PCR experiments and subsequent genotyping of mice (Figure $1 \mathrm{~A}$ and Supplementary Table 1 for primer sequence and PCR programs).

\section{Genotyping of mouse lines}

Four weeks after birth, 2-3 mm tail sections were cut of each mice, placed into $1.5 \mathrm{ml}$ Eppendorf tubes, and stored at $-80^{\circ} \mathrm{C}$. To lyse the tail tissue, $400 \mu \mathrm{l}$ of lysis buffer [48], and incubated at $55^{\circ} \mathrm{C}$ over night while shaking at $220 \mathrm{rpm}$. Then, the lysates were incubated at $95-100^{\circ} \mathrm{C}$ for $30 \mathrm{~min}$ to inactivate the proteinase $\mathrm{K}$, the tubes were centrifuged at full speed for $10 \mathrm{sec}$, and $2 \mu \mathrm{l}$ of the lysates were used for the genotyping PCR (Supplementary Table 1).

\section{Maintenance of mouse colonies}

All animals were kept in the CNIO animal facility according to the facility norms based on the Real Decreto 1201/2005 and sacrificed by $\mathrm{CO}_{2}$ inhalation either within a programmed procedure or as a humane endpoint when animals showed signs of significant sickness. PSA61CRE mice were a kind gift from Prof. J Trapman. PTEN KO mice were a kind gift of Prof $\mathrm{H}$. Wu.

\section{Analysis of transgene expression at the RNA level and Q-RT-} PCR.

The expression of different transcripts in tissues was analyzed by reverse transcription-PCR (RT-PCR). Total RNA was isolated using TRI-REAGENT (Molecular Research Center, Cincinnati Ohio), treated with DNase (Roche), and reverse transcribed using random hexamer primers (Promega) and reverse transcriptase (Promega). The cDNA was amplified using specific primer combinations as described in Supplementary Table 2. Quantitative measurements were performed by purifying total mRNA using TRI-REAGENT (Molecular Research Center, Cincinnati Ohio). Reverse transcription was performed with 5 $\mu \mathrm{g}$ of mRNA using MMLV reverse transcriptase (Promega) and oligo dT primers. Real-time PCR was performed using an ABI 7900HT (Applied Biosystems) as indicated in [48]. The reaction was carried out in 96-well plates and QPCR reactions were run using Taqman Gene Expression assays (Applied Biosystems). Detection of GAPDH was used as an internal control. Relative quantitation values were expressed as Log10 of Relative Quantity. Relative Quantity and statistical analysis for QPCR data were calculated using Applied Biosystem RQ Manager 1.2.1 software.

\section{Carcinogenesis induced by testosterone and estradiol}

We used mice with an average age of 8 weeks. The hormones testosterone (Sigma) and $\beta$-Estradiol (Sigma) were mixed with colorless silicone (Soudal) and dried for $48 \mathrm{~h}$. Pellets were stamped out using a $5 \mathrm{~mm}$ biopsy punch (Stieffel), resulting in a $30 \mathrm{mg}$ hormone/silicone pellet. A $5 \mathrm{~mm}$ incision was made on the lower back (after anesthesia with $2 \%$ isofluorane), and the pellets were inserted under the fur. The procedure was repeated after 8 weeks. The total doses of the implanted hormones are as follows: Implanted total 1st dose at 8 weeks of age: Testosterone: $12.5 \mathrm{mg}$; $\beta$-Estradiol: $1.25 \mathrm{mg}$.

Implanted total 2 nd dose at 16 weeks of age: Testosterone: 18.75 mg; $\beta$-Estradiol: $1.87 \mathrm{mg}$.

To ensure the health of the animals, the mice were monitored every 24-48 h, depending on the health status of each animal.

\section{Necropsy and pathological analysis}

Tissues were fixed in $10 \%$ formalin for $24 \mathrm{~h}$, dehydrated at different ethanol concentrations with xylol and embedded in paraffin at $65^{\circ} \mathrm{C}$. Tissue fixation and paraffin embedding were carried out at the Histopatology Unit at the CNIO.

\section{Statistical data analysis}

To determine the statistical significance of the lesions and the statistical significance of the differences in the incidence of pyelonephritis, either a one-way ANOVA or a one-tailed Student's $\mathrm{t}$-test were used as indicated in the figure legends.

\section{Immunohistochemistry}

Prepared paraffin tissue blocks were cut into $2 \mu \mathrm{m}$ sections using an automated microtome and the sections were dyed with $\mathrm{H} \& \mathrm{E}$ or various antibodies. All staining were carried out at the Compared Pathology Unit at the CNIO according to established protocols. We used the following antibodies: anti-p21 from Santa Cruz (sc-397-G) and horseradish peroxidase (goat anti-rabbit) secondary from Dako (P0448).

\section{Results}

\section{Generation of transgenic mice carrying the PIM1 transgene}

We generated mouse lines that conditionally express the Pim1 transgene by inserting a stop cassette flanked by LoxP sequences. These lines were crossed with a transgenic mouse line expressing Cre recombinase under the control of the PSA promoter, allowing CRE expression primarily in prostate. Upon Cre recombinase expression, the stop cassette would be excised allowing Pim1 transgene transcription (Figure 1A). We identified two Pim1 transgenic founder mice that clearly expressed the Pim1 transgene under PSA-Cre control in the prostate (Figure 1B). However, upon hormone treatment (estradiol+testosterone), we found that the Piml transgene was also expressed in bladder tissues (Figures $1 \mathrm{~B}$ and $1 \mathrm{C}$ ).

As Pim1 is regarded a "weak" oncogene, we decided to study the induction of bladder hyperplasia solely by Pim1 overexpression, as well as the effect of Pim1 overexpression in the absence of one Pten allele. To that end, we used conditional knock-out mice bearing a floxed Pten allele. Upon Cre recombinase expression, the Pten allele will be inactivated by excision of exon 5 of the Pten gene [49] in cells in which Pim1 transcription is activated. A summary of the mouse line genotypes used in this study are as follows: $\operatorname{tgPim} 1[\mathrm{Pim} 1(\mathrm{Tg} /+)$;PSA- 
Citation: Grassow MN, Aparicio CB, Cecilia Y, Perez M, Galvan SM, et al. (2014) Pim1 Kinase Cooperates with Hormone Treatment to Promote Bladder and Ureteral Urothelial Hyperplasia. J Carcinog Mutagen 5: 161. doi:10.4172/2157-2518.1000161
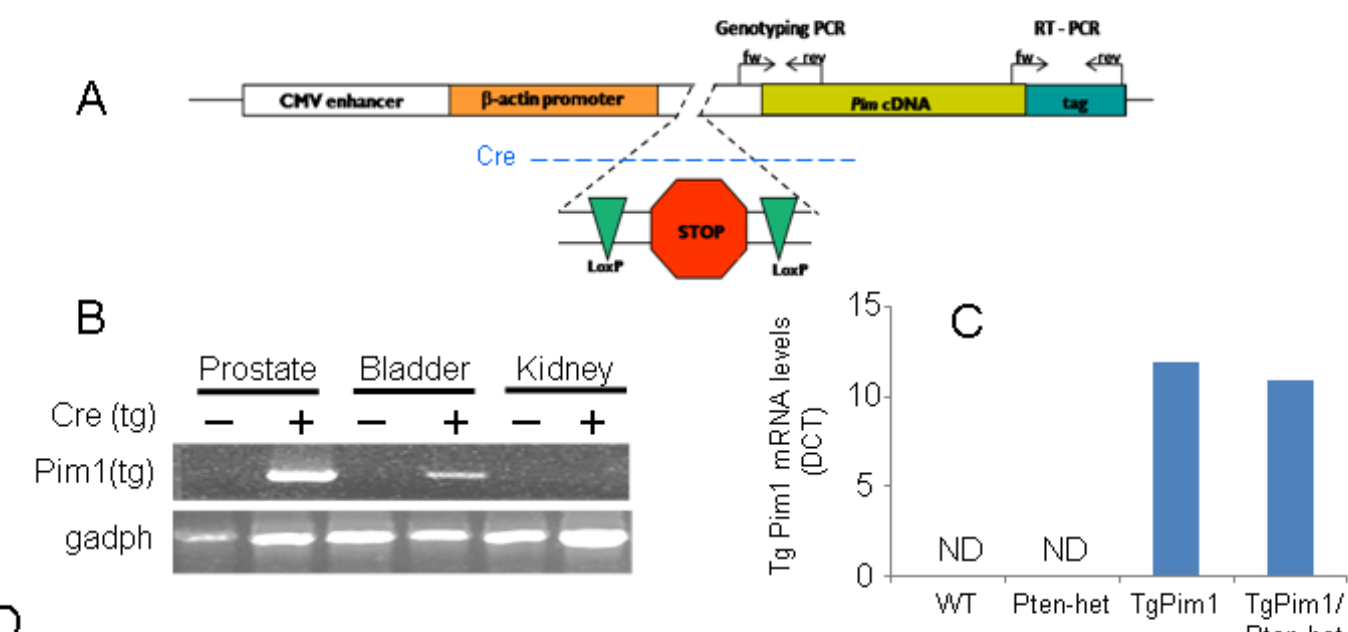

D

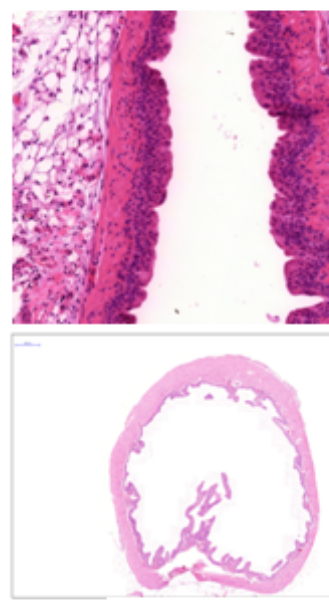

$\operatorname{Pim} 1(\operatorname{tg})$

No treatment
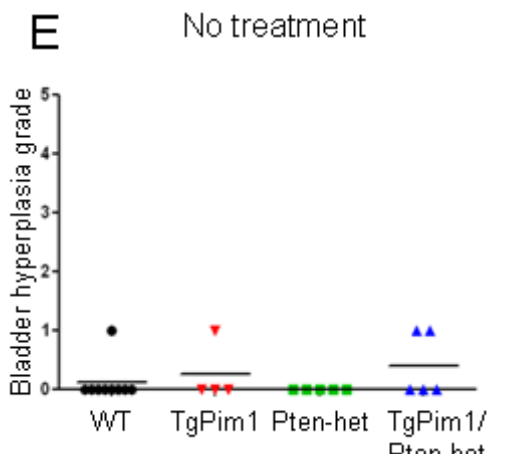

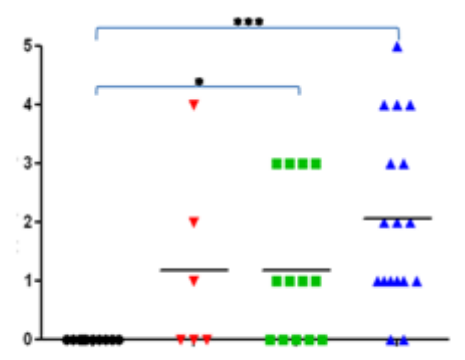

WT TgPim1 Pten-het TgPim1/

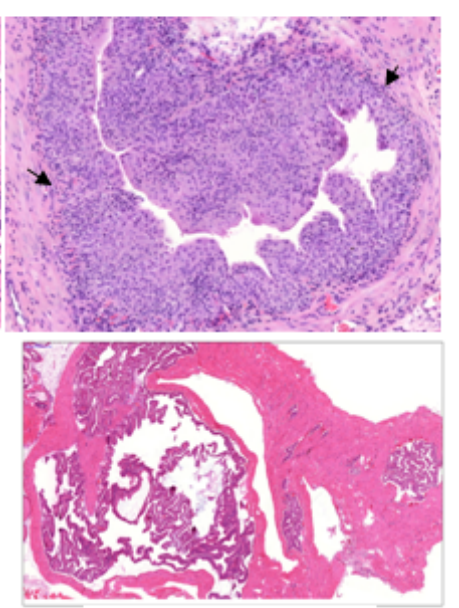

Pim1(tg) 2 rounds

2 rounds

Testosterone+estradiol

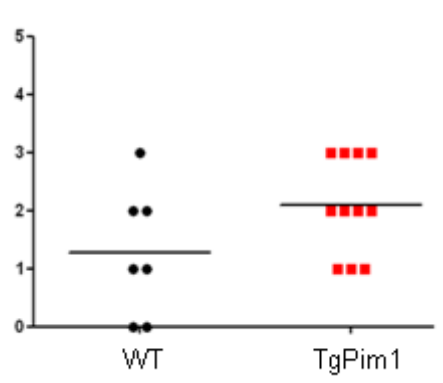

Figure 1: (A) Scheme of the transgene strategy used. (B) Relative expression of PIM1 in Pim1/PSA-Cre mice after 2 rounds of hormone treatment. RNA was extracted from different tissues of 24 weeks old mice after testosterone and estradiol treatment. Reverse transcriptase PCR was performed to obtain cDNA, which was amplified using specifically designed primers. PCR fragment length was checked on a $1.5 \%$ agarose gel. (C) Levels of transgenic PIM1 mRNA determined by quantitative RT-PCR. Graph shows average levels of expression in the bladder of PIM1 mRNA of per genotype performed in triplicate. Data were normalized to the endogenous levels of GADPH in each sample. ND: Not detected. Transgenic PIM1 mRNA was not detected in WT or PTEN-Het mice. (D) Urothelial hyperplasia in hormone treated mice. To determine the development of urothelial hyperplasia due to hormone treatment, 8-week-old untreated mice of each genotype and hormone treated mice of corresponding genotypes, were sacrificed and bladder tissue was taken and distended with fixative (10\% formalin). Upper pictures: Representative hyperplasia observed in bladder walls. Bottom pictures: Pictures show representative increases in bladder size over treatment course. H\&E staining of bladders from tgPim1 mice before treatment and after 1 or 2 treatment rounds, respectively. All pictures were taken at the same magnification, (Panoramic viewer - ZeissE) Urothelial hyperplasia grades reached. (E) Grading of hyperplasia in the different conditions. Hyperplasia of epithelial cells in bladder, before and after hormone treatment, was graded using the following grading scale: bh-grade 0: normal (2-3 cell layers); bh-grade 1: slight hyperplasia (4 cell layers); bh-grade 2: slight/moderate hyperplasia (5-8 cell layers); bh-grade 4: moderate hyperplasia (9-10 cell layers); bh-grade 4: moderate/severe hyperplasia (11-12 cell layers); bh-grade 5: severe hyperplasia (>12 cell layers). See text for details. 
Citation: Grassow MN, Aparicio CB, Cecilia Y, Perez M, Galvan SM, et al. (2014) Pim1 Kinase Cooperates with Hormone Treatment to Promote Bladder and Ureteral Urothelial Hyperplasia. J Carcinog Mutagen 5: 161. doi:10.4172/2157-2518.1000161

\begin{tabular}{|c|c|c|}
\hline $\begin{array}{c}\text { Bladder } \\
\text { hyperplasia grade } \\
\text { (bh-grade) }\end{array}$ & Effect on bladder & Cell layers \\
\hline 0 & Normal & $2-3$ \\
\hline 1 & Slight hyperplasia & 4 \\
\hline 2 & Slight/moderate hyperplasia & $5-8$ \\
\hline 3 & Moderate hyperplasia & $9-10$ \\
\hline 4 & Moderate/severe hyperplasia & $10-12$ \\
\hline 5 & Severe hyperplasia & $>12$ \\
\hline
\end{tabular}

Table 1: Classification of bladder hyperplasia in mice after hormone treatment. Bladder hyperplasia grade (bh-grade) was established on bladder tissue that was extended with fixative ( $10 \%$ formalin) at necropsy.

CRE (Tg/+)], Pten-Het [Pten(loxp/+);PSA-CRE (Tg/+)], tgPim1/PtenHet $[\operatorname{Pim} 1(\mathrm{Tg} /+) ; \operatorname{Pten}(\operatorname{loxp} /+) ; \operatorname{PSA}-\mathrm{CRE}(\mathrm{Tg} /+)]$.

We measured the levels of Pim1 transgene expression by quantitative RT-PCR in bladder tissues from all strains and found that the levels of Pim1 transgene expression in the bladder were not as high as in prostate (Figure 1B) but were specific to mice expressing Cre recombinase (Figure 1C) upon hormone treatment.

Hormone treatment induces urothelial hyperplasia in the bladder of mice overexpressing Piml alone or with simultaneous loss of one Pten allele.

Hormone treatment protocols, such as those used in this work, have not been reported to cause urothelial hyperplasia or severe bladder pathology. However, we detected an increase in general bladder size (Figure 1D) A large and macroscopically pathological bladder was only evident after hormone treatment and correlated with the expression of the Pim1 transgene or the loss of one Pten allele.

To explore the observed bladder hyperplasia, we decided to analyze

A

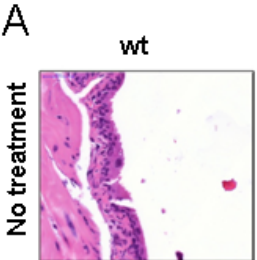

$\operatorname{tg} \operatorname{Pim} 1$

PTENHet $\operatorname{tg} \operatorname{Pim} 11$
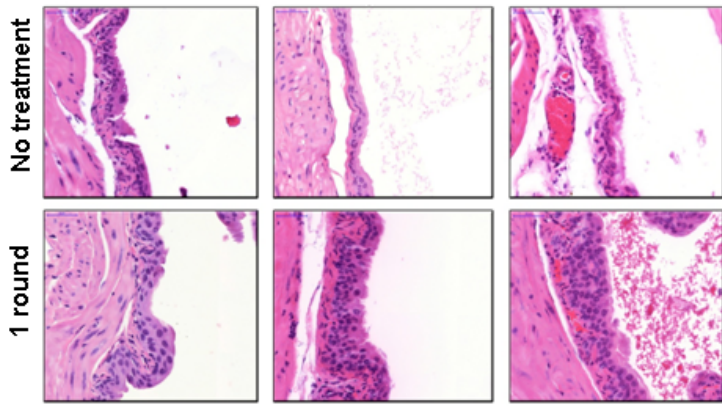

PTENHet
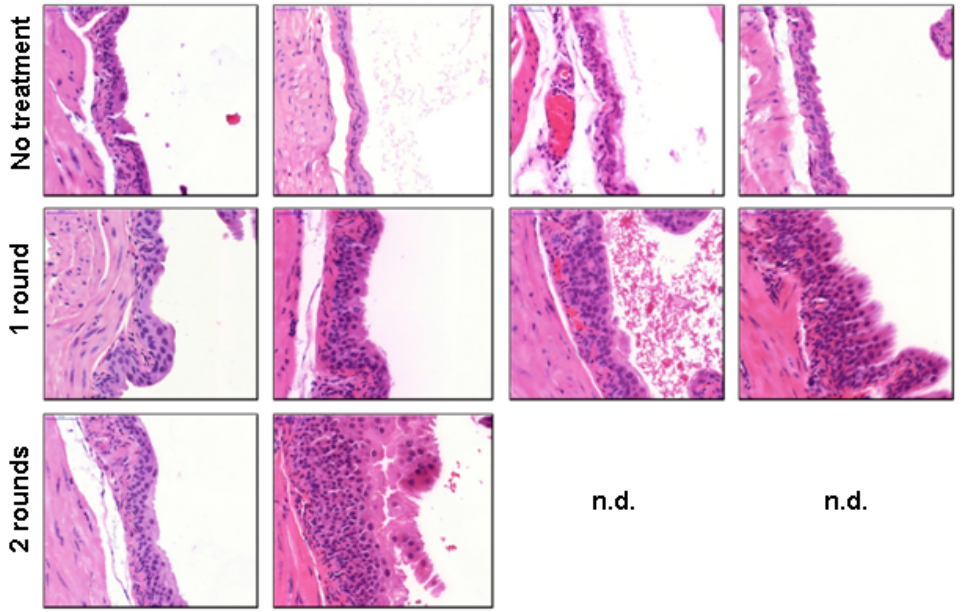

n.d.

n.d.
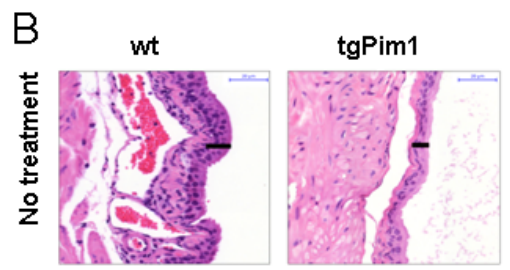

PTENHet
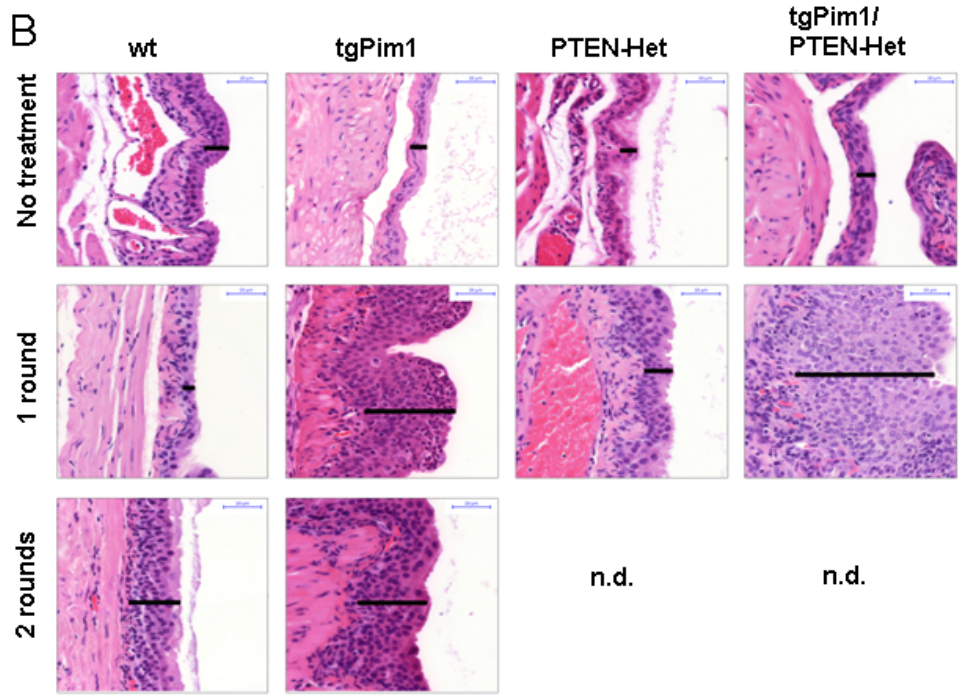

n.d.

n.d.

Figure 2: Urothelial hyperplasia developed after hormone treatment. Example for (A) average of hyperplasia grade observed in each genotype (B) maximum of hyperplasia grade in each genotype. To determine the development of urothelial hyperplasia due to hormone treatment, 8-week-old untreated mice of each genotype and hormone treated mice ( 1 or 2 rounds) of corresponding genotypes were sacrificed and the bladder was taken. H\&E staining of bladder tissue was used for grading and statistics as shown in Figure 1D. 
Citation: Grassow MN, Aparicio CB, Cecilia Y, Perez M, Galvan SM, et al. (2014) Pim1 Kinase Cooperates with Hormone Treatment to Promote Bladder and Ureteral Urothelial Hyperplasia. J Carcinog Mutagen 5: 161. doi:10.4172/2157-2518.1000161

the bladder epithelia microscopically (Figure 1E). Hyperplasia of epithelial cells in the bladder before and after hormone treatment was graded using the grading scale shown on Table 1. After one treatment round, wild type mice showed no hyperplasia (bh-grade 0 ), tgPim1 mice displayed mostly bh-grade 1 (Figures $1 \mathrm{E}$ and $2 \mathrm{~A}$ ) reaching the maximum of bh-grade 3 (Figures $1 \mathrm{D}$ and $2 \mathrm{~B}$ ), and PTEN-Het mice primarily displayed bh-grade 1 (Figures $1 \mathrm{D}$ and $2 \mathrm{~A}$ ) with 3 animals reaching bh-grade 3 (Figure $2 \mathrm{~B}$ ). The increase in urothelial hyperplasia was even more significant in tgPim1/PTEN-Het mice, where several animals displayed bh-grade 4 and 1 animal reached bh-grade 5 (Figures $1 \mathrm{D}$ and $2 \mathrm{~B})$.

\section{Hormone treatment induces hyperplasia of the ureter in mice overexpressing Pim1 alone or in combination with loss of one Pten allele.}

Similarly, we analyzed the epithelial layers of the ureter in
A

1 round

Testosterone+estradiol

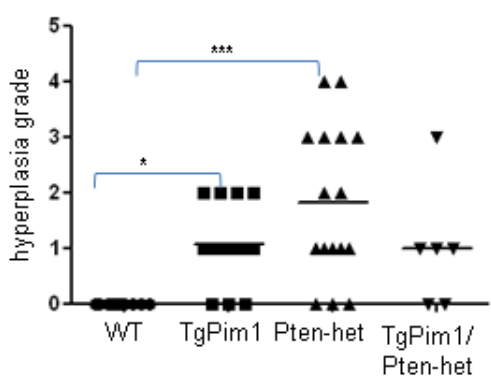

2 rounds

Testosterone+estradiol

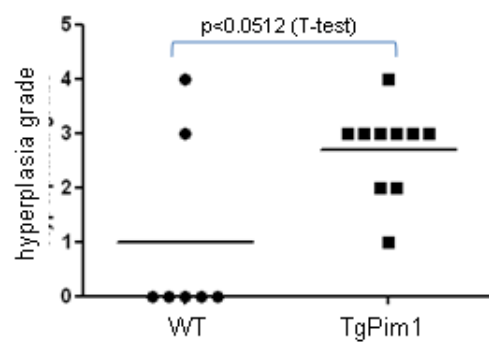

B

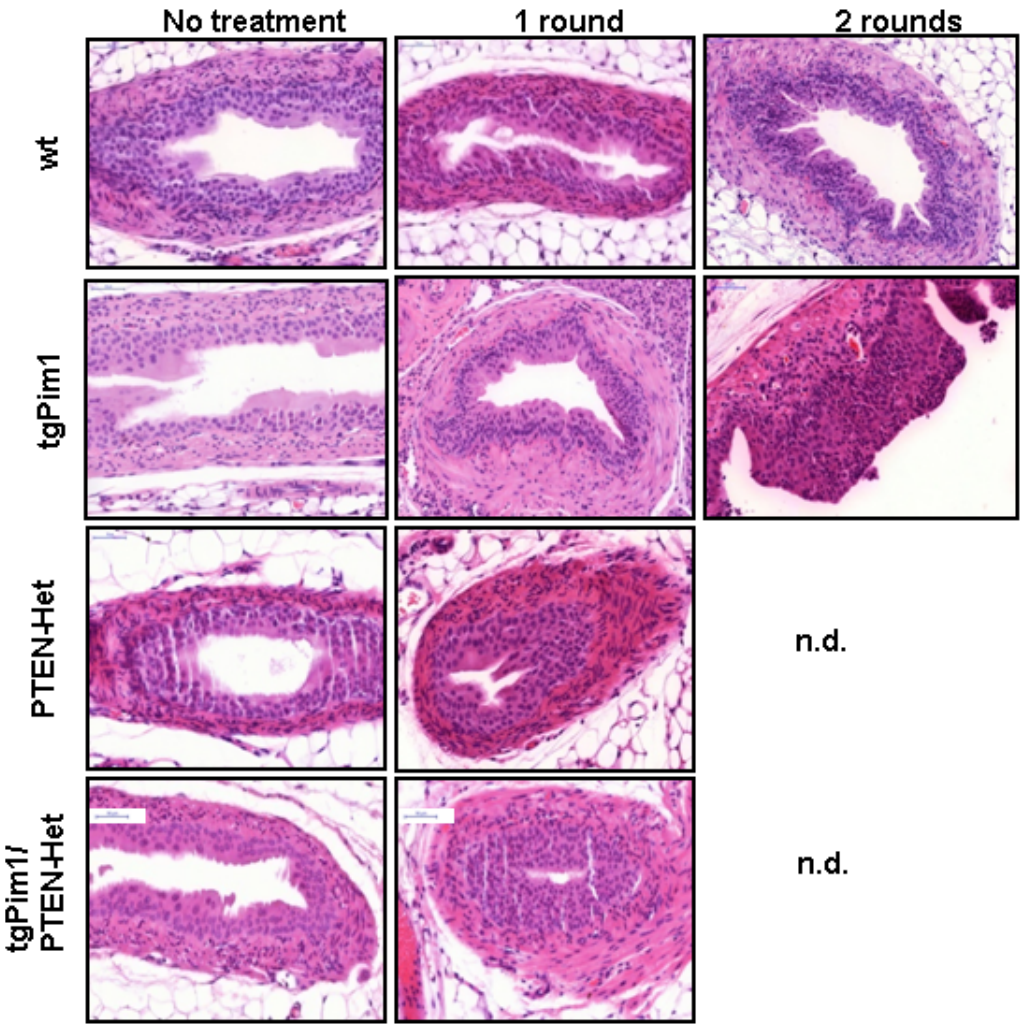

Figure 3: Ureter hyperplasia in hormone treated mice. To determine the development of ureteral hyperplasia due to hormone treatment, 8 week old untreated mice of each genotype and hormone treated mice of corresponding genotypes were sacrificed and ureter taken and distended with fixative (10\% formalin). (A) Ureteral hyperplasia grades reached. Hyperplasia of epithelial cells in the ureter before and after hormone treatment was graded using a similar grading scale to the bladder: grade 0: normal (2-3 cell layers); grade 1: slight hyperplasia (4 cell layers); grade 2: slight/moderate hyperplasia (5-8 cell layers); grade 4: moderate hyperplasia (910 cell layers); grade 4: moderate/severe hyperplasia (11-12 cell layers); grade 5: severe hyperplasia ( $>12$ cell layers). See text for details. (B) Example for average hyperplasia grade observed in each genotype. To determine the development of ureteral hyperplasia due to hormone treatment, 8-week-old untreated mice of each genotype and hormone treated mice (1 or 2 rounds) of corresponding genotypes were sacrificed and ureters were taken. 
transgenic animals subjected to hormone treatments. As in the bladder, we observed an increase in ureteral hyperplasia (Figure 3). This hyperplasia clearly decreases the light of the ureter, reaching full occlusion after one treatment round in some cases in tgPim1/Pten-Het mice or after 2 hormone treatment rounds in tgPim 1 mice (Figure 3B).

Pim1 and Pim2 phosphorylate the cell cycle inhibitor p21(Cip1/ WAF1) (p21) on Thr145 in vitro and in vivo [23]. It has been reported that the overexpression of Pim kinases in cells leads to the increased stability of p21 and results in enhanced levels of endogenous p21 proteins [50,51]. Knockdown of Pim expression via siRNA results in reduced expression of endogenous p21, indicating that Pims are legitimate p21 kinases regulating p21 stability. To explore whether Pim 1 overexpression triggers the stabilization of $\mathrm{p} 21$, we quantified the number of cells showing p21 nuclear staining for all lesion grades in all cohorts. We observed an increased number of umbrella cells with p21 in high-grade lesions (Figures 4A and 4B) (tgPim1, Pten-Het and tgPim1/Pten-Het genotypes) but not in hyperplastic tissues. We did not observe a high number of cells showing nuclear staining for $\mathrm{p} 21$ in low-grade hyperplasias in any cohort.

\section{High incidence of pyelonephytis}

When correlating the genotypes with the treatments in which we observed increased urothelial hyperplasia (especially in tgPim1/PtenHet mice after one treatment round or tgPim 1 mice after 2 hormone treatment rounds), which lead to ureter occlusion, we observed a high incidence of pyelonephritis (Figure 5), with up to $50 \%$ of the animals with this specific genotype developing this disease. As pyelonephritis is quite painful and leads to death within 12-24 hours, the animals were sacrificed at the earliest sign of kidney and or urination problems; no further rounds of hormone treatment were performed due to the high rate of affected animals.
Due to the significantly increased incidence of pyelonephritis in $\operatorname{tgPim} 1 /$ Pten-Het mice during the first round of hormone treatment, a second round of treatment was not administered and humane euthanasia was performed. However, we were able to administer a second round of hormone treatment to the WT and tgPim 1 mice. It is interesting to note that after one round of treatment, PTEN-het mice did not develop pyelonephritis while WT mice did not develop disease after 2 rounds. This clearly indicates a role for Pim 1 in the secondary development of this disease, most likely due to induced bladder and ureter hyperplasia in these transgenic mice.

\section{Discussion}

The hormone treatment classically used to induce prostatic lesions is not known to induce urothelial hyperplasia. Nevertheless, we detected moderate to severe urothelial hyperplasia in $30 \%$ of tgPIM1/Pten-Het and Pten-Het mice and light to moderate urothelial hyperplasia in $30 \%$ of tgPIM1 mice after one round of hormone treatment. There was no observed urothelial hyperplasia in untreated 10-month old mice of any genotype.

The PSA/Cre mouse model used in this study has been demonstrated to express the induced transgene not only in prostate tissue but also in bladder after hormone treatment. We did not detect expression of Pim1 in the bladder of untreated 10 week-old mice of any genotype, but there was detectable expression Pim 1 after 1 or 2 rounds of hormone treatment in 24-week old tgPIM1 mice. We do not know the reasons for this unspecific expression of transgene in bladder upon hormone treatment. It is possible that as testosterone activates PSA transcription, the levels of testosterone generated by hormone treatment might be sufficient to induce PSA promoter transcription in bladder, and therefore CRE expression, and might thus activate Pim1
A

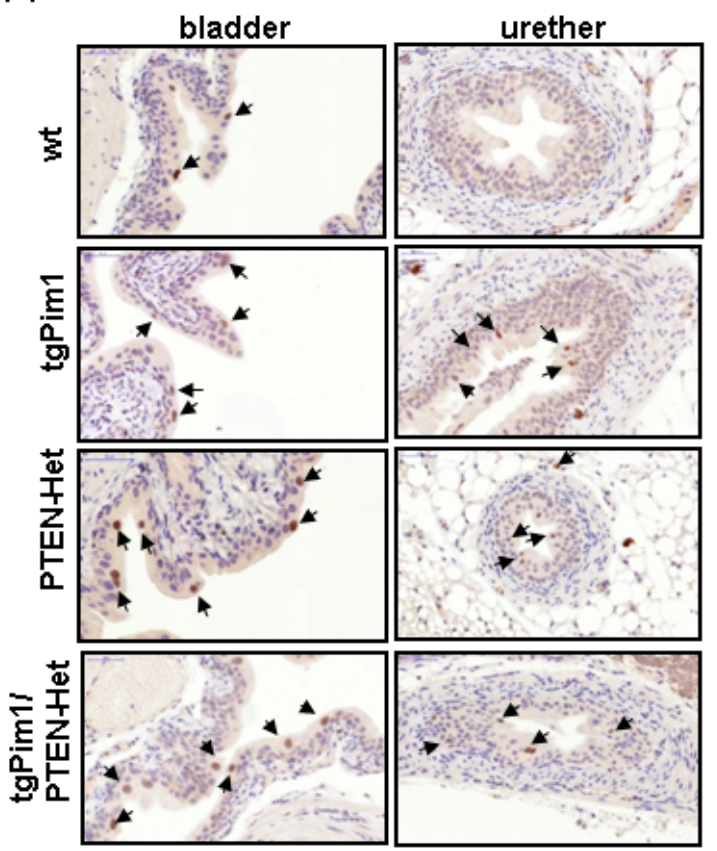

B

\begin{tabular}{|c|c|c|}
\hline & Bladder & Urether \\
\hline WT & $4 \pm 4$ & $3 \pm 3$ \\
\hline tgPIM1 & $8 \pm 4$ & $6 \pm 2$ \\
\hline PTEN-het & $14 \pm 6$ & $8 \pm 3$ \\
\hline $\begin{array}{c}\text { tgPIM1/ } \\
\text { PTEN-het }\end{array}$ & $20 \pm 10$ & $10 \pm 4$ \\
\hline
\end{tabular}

Figure 4: p21waf1 nuclear stabilization in urothelial lesions. (A) Representative pictures. To examine p21waf1 in urothelial lesions, immunohistochemistry for p21 was performed in the bladder and ureter tissues of 16-week-old hormone-treated mice showing high grade and low-grade lesions. Picture shows p21waf1 staining in bladder and ureter lesions. Arrows show nuclear staining for p21waf1. (B) Average ( \pm SD) percentage of nuclear p21 positive cells per genotype. 

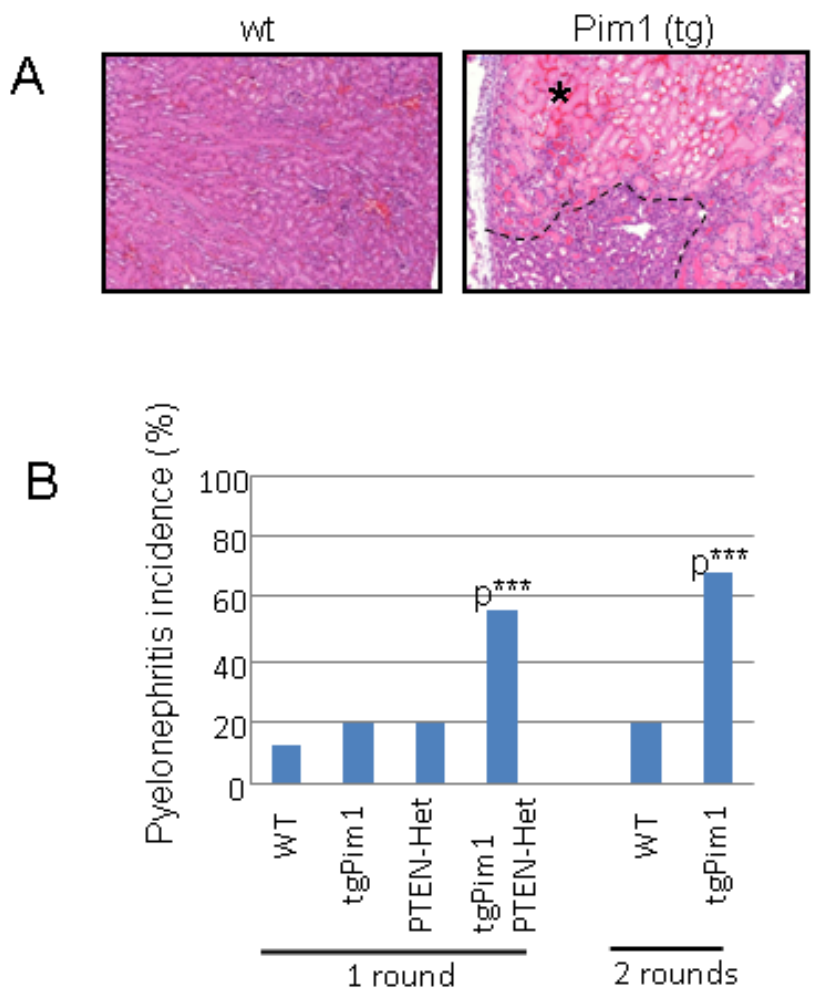

Figure 5: Pyelonephritis incidence in hormone-treated mice. (A) H\&E staining of a healthy kidney from a 24 week-old WT mouse (left) vs. a kidney displaying pyelonephritis from a 24-week-old tgPim1 mouse, both after 2 rounds of hormone treatment (right). Note the areas of renal infarct in the animal with pyelonephritis, in which more than one-third of the parenchyma is affected. (B) Percentage of pyelonephritis incidence in every genotype after 1 or 2 rounds of hormone treatment, respectively.

expression. This theory is supported by evidence that PSA is expressed in some bladder carcinomas [52-54].

The observation that hormone treatment induced urothelial hyperplasia suggests that, in a carcinogen-prone environment, Pim1 alone is able to induce hyperplasia. The same can be said for the loss of one Pten allele. Consistent with published data indicating that PTEN inactivation has a role in promoting bladder cancer [55], Pten-Het mice show a significant increase in urothelial hyperplasia compared to wild type mice. TgPIM1/Pten-Het mice show an increased severity of hyperplasia in the bladder, confirming the cooperation between Pten loss and Pim1 overexpression in hormone-induced hyperplasia.

In parallel to this work, we generated conditional Pim1 transgenic mice expressing Pim1 in prostate epithelium, and analyzed the contribution of PIM1 to neoplastic initiation and progression [48]. Accordingly, we explored the effect of PIM1 overexpression in the same settings as this work, upon hormone treatment, during aging, and in combination with the absence of one Pten allele. We have found that Pim1 overexpression increased the severity of mouse prostate intraepithelial neoplasias moderately in all three settings. Analysis of senescence induced in these prostatic lesions suggests that Pim1induced hyperplasias do not progress to malignant state due to the induction of senescence.

As in this and other transgenic or KO models [56-60], our model showed that increased expression of Pim1, alone or in combination with loss of one Pten allele, was not sufficient to produce tumors; however, Pim expression clearly contributed to the increased severity of hyperplasias in a manner similar to what has been reported in other models [61]. But in other models, especially prostate, an increase in senescence markers was observed in high-grade hyperplasias correlating with observations suggesting that senescence might regulate the transition from hyperplasia to carcinoma $[55,62,63]$.

The process of senescence increases the levels of senescence markers such as p21waf1, p16ink4a, and p19ARF in the cell nucleus. As none of the 16-week-old hormone-treated mice and 10-month-old untreated mice displayed bladder tumors, we sought to determine senescence levels in the urothelial tissues of mice of each genotype using the markers p21, p16, and p19. The quantification of all three markers for all lesion grades in all cohorts showed an increased number of cells with p21waf1 in umbrella cells in high-grade lesions (tgPim1, Pten-Het, and tgPim1/ Pten-Het genotypes). However, we did not observe significant nuclear staining for p16 or p19 in any sample, indicating that senescence is not the primary response induced by Pim 1 overexpression in bladder at difference of prostate. Or alternatively, the effectors of this senescence process are different.

Finally, Pim1 overexpression-induced hyperplasia in bladder and ureters may lead to light occlusion, inducing pyelonephritis in transgenic animals. This severe phyelonephritis effect may be due to a combination of hyperplasia in bladder and ureters and the hormoneinduced prostatic inflammation and hyperplasia observed in PIM1 transgenic mice [48] that could partly obstruct the urinary tract causing urinary reflux, thus contributing to pyelonephritis. This is also supported by works reporting that hormone treatment can lead to bladder outlet obstruction and voiding dysfunction in male mice [64].

The overexpression of PIM1 transgene in prostate leads to an impaired immune response in hormone-treated mice which seems to be related to pyelonephritis and to the absence of senescence markers in prostate neoplasia [48]. However, in ureter and bladder, the immunoresponse was not found significantly increased in any of the genotypes.

Summaryzing, our data suggest that Pim1 might contribute to progression rather than initiation of urothelial neoplasia and that urothelial hyperplasia is an important factor in the development of pyelonephritis.

\section{Acknowledgements}

We thank Dr. Trapman J for the kind gift of the PSA61-CRE mice and Dr. Wu H for the kind gift of the PTEN KO mice. We would like to acknowledge the excellen technical work of Virginia Álvarez, Maria del Carmen Arriba, Elvira Gil, María Gómez, Patricia González and Natalia Matesanz of the Comparative Pathology Core Unit at CNIO. This work was supported by grants from Spanish Ministry of Economy and Competitivity, ISCIII (Fis: PI12/00137, RTICC: RD12/0036/0028), Consejeria de Ciencia e Innovacion (CTS-6844) and Consejeria de Salud of the Junta de Andalucia (PI-0135-2010 and PI-0306-2012). MN-G was funded by a fellowship from the Spanish Ministry of Science and Innovation.

\section{References}

1. Brault L, Gasser C, Bracher F, Huber K, Knapp S, et al. (2010) PIM serine/ threonine kinases in the pathogenesis and therapy of hematologic malignancies and solid cancers. Haematologica 95: 1004-1015.

2. Eichmann A, Yuan L, Bréant C, Alitalo K, Koskinen PJ (2000) Developmental expression of pim kinases suggests functions also outside of the hematopoietic system. Oncogene 19: 1215-1224.

3. Bullock AN, Debreczeni J, Amos AL, Knapp S, Turk BE (2005) Structure and substrate specificity of the Pim-1 kinase. J Biol Chem 280: 41675-41682.

4. Mukaida N, Wang YY, Li YY (2011) Roles of Pim-3, a novel survival kinase, in tumorigenesis. Cancer Sci 102: 1437-1442. 
Citation: Grassow MN, Aparicio CB, Cecilia Y, Perez M, Galvan SM, et al. (2014) Pim1 Kinase Cooperates with Hormone Treatment to Promote Bladder and Ureteral Urothelial Hyperplasia. J Carcinog Mutagen 5: 161. doi:10.4172/2157-2518.1000161

Page 8 of 9

5. Mikkers H, Nawijn M, Allen J, Brouwers C, Verhoeven E, et al. (2004) Mice deficient for all PIM kinases display reduced body size and impaired responses to hematopoietic growth factors. Mol Cell Biol 24: 6104-6115.

6. Narlik-Grassow M, Blanco-Aparicio C, Cecilia Y, Peregrina S, Garcia-Serelde B, et al. (2012) The essential role of PIM kinases in sarcoma growth and bone invasion. Carcinogenesis 33: 1479-1486.

7. Hogan C, Hutchison C, Marcar L, Milne D, Saville M, et al. (2008) Elevated levels of oncogenic protein kinase Pim-1 induce the p53 pathway in cultured cells and correlate with increased Mdm2 in mantle cell lymphoma. J Biol Chem 283: 18012-18023.

8. Wang Z, Bhattacharya N, Weaver M, Petersen K, Meyer M, et al. (2001) Pim-1: a serine/threonine kinase with a role in cell survival, proliferation, differentiation and tumorigenesis. J Vet Sci 2: 167-179.

9. White $E$ (2003) The pims and outs of survival signaling: role for the Pim-2 protein kinase in the suppression of apoptosis by cytokines. Genes Dev 17: 1813-1816.

10. Peltola KJ, Paukku K, Aho TL, Ruuska M, Silvennoinen O, et al. (2004) Pim-1 kinase inhibits STAT5-dependent transcription via its interactions with SOCS1 and SOCS3. Blood 103: 3744-3750.

11. Chen J, Kobayashi M, Darmanin S, Qiao Y, Gully C, et al. (2009) Hypoxiamediated up-regulation of Pim-1 contributes to solid tumor formation. Am J Pathol 175: 400-411.

12. Zhao Y, Hamza MS, Leong HS, Lim CB, Pan YF, et al. (2008) Kruppel-like factor 5 modulates $\mathrm{p} 53$-independent apoptosis through Pim1 survival kinase in cancer cells. Oncogene 27: 1-8.

13. Hoover DS, Wingett DG, Zhang J, Reeves R, Magnuson NS (1997) Pim-1 protein expression is regulated by its 5 -untranslated region and translation initiation factor elF-4E. Cell Growth Differ 8: 1371-1380.

14. Mizuno K, Shirogane T, Shinohara A, Iwamatsu A, Hibi M, et al. (2001) Regulation of Pim-1 by Hsp90. Biochem Biophys Res Commun 281: 663-669.

15. Wang Z, Weaver M, Magnuson NS (2005) Cryptic promoter activity in the DNA sequence corresponding to the pim-1 5'-UTR. Nucleic Acids Res 33: 22482258.

16. Shay KP, Wang Z, Xing PX, McKenzie IF, Magnuson NS (2005) Pim-1 kinase stability is regulated by heat shock proteins and the ubiquitin-proteasome pathway. Mol Cancer Res 3: 170-181.

17. Breuer M, Slebos R, Verbeek S, van Lohuizen M, Wientjens E, et al. (1989) Very high frequency of lymphoma induction by a chemical carcinogen in pim-1 transgenic mice. Nature 340: 61-63.

18. van Lohuizen M, Verbeek S, Krimpenfort P, Domen J, Saris C, et al. (1989) Predisposition to lymphomagenesis in pim-1 transgenic mice: cooperation with c-myc and N-myc in murine leukemia virus-induced tumors. Cell 56: 673-682.

19. Allen JD, Verhoeven E, Domen J, van der Valk M, Berns A (1997) Pim-2 transgene induces lymphoid tumors, exhibiting potent synergy with c-myc. Oncogene 15: 1133-1141.

20. Allen JD, Berns A (1996) Complementation tagging of cooperating oncogenes in knockout mice. Semin Cancer Biol 7: 299-306.

21. Wang J, Anderson PD, Luo W, Gius D, Roh M, et al. (2012) Pim1 kinase is required to maintain tumorigenicity in MYC-expressing prostate cancer cells. Oncogene 31: 1794-1803.

22. Nawijn MC, Alendar A, Berns A (2011) For better or for worse: the role of Pim oncogenes in tumorigenesis. Nat Rev Cancer 11: 23-34.

23. Wang Z, Bhattacharya N, Mixter PF, Wei W, Sedivy J, et al. (2002) Phosphorylation of the cell cycle inhibitor p21Cip1/WAF1 by Pim-1 kinase. Biochim Biophys Acta 1593: 45-55.

24. Morishita D, Katayama R, Sekimizu K, Tsuruo T, Fujita N (2008) Pim kinases promote cell cycle progression by phosphorylating and down-regulating p27Kip1 at the transcriptional and posttranscriptional levels. Cancer Res 68: 5076-5085.

25. Mochizuki T, Kitanaka C, Noguchi K, Muramatsu T, Asai A, et al. (1999) Physical and functional interactions between Pim-1 kinase and Cdc25A phosphatase. Implications for the Pim-1-mediated activation of the c-Myc signaling pathway. J Biol Chem 274: 18659-18666.

26. Aho TL, Sandholm J, Peltola KJ, Mankonen HP, Lilly M, et al. (2004) Pim-1 kinase promotes inactivation of the pro-apoptotic Bad protein by phosphorylating it on the Ser112 gatekeeper site. FEBS Lett 571: 43-49.

27. Gu JJ, Wang Z, Reeves R, Magnuson NS (2009) PIM1 phosphorylates and negatively regulates ASK1-mediated apoptosis. Oncogene 28: 4261-4271.

28. Aho TL, Sandholm J, Peltola KJ, Ito Y, Koskinen PJ (2006) Pim-1 kinase phosphorylates RUNX family transcription factors and enhances their activity. BMC Cell Biol 7: 21.

29. Koike N, Maita H, Taira T, Ariga H, Iguchi-Ariga SM (2000) Identification of heterochromatin protein 1 (HP1) as a phosphorylation target by Pim-1 kinase and the effect of phosphorylation on the transcriptional repression function of HP1(1). FEBS Lett 467: 17-21.

30. Evans KE, Fox SW (2007) Interleukin-10 inhibits osteoclastogenesis by reducing NFATc1 expression and preventing its translocation to the nucleus. BMC Cell Biol 8: 4.

31. Rainio EM, Sandholm J, Koskinen PJ (2002) Cutting edge: Transcriptiona activity of NFATc1 is enhanced by the Pim-1 kinase. J Immunol 168: 1524 1527

32. Winn LM, Lei W, Ness SA (2003) Pim-1 phosphorylates the DNA binding domain of c-Myb. Cell Cycle 2: 258-262.

33. Ishibashi Y, Maita H, Yano M, Koike N, Tamai K, et al. (2001) Pim-1 translocates sorting nexin 6/TRAF4-associated factor 2 from cytoplasm to nucleus. FEBS Lett 506: 33-38.

34. Hammerman PS, Fox CJ, Birnbaum MJ, Thompson CB (2005) Pim and Akt oncogenes are independent regulators of hematopoietic cell growth and survival. Blood 105: 4477-4483.

35. Selten G, Cuypers HT, Boelens W, Robanus-Maandag E, Verbeek J, et al. (1986) The primary structure of the putative oncogene pim-1 shows extensive homology with protein kinases. Cell 46: 603-611.

36. Cuypers HT, Selten G, Berns A, Geurts van Kessel AH (1986) Assignment of the human homologue of $\mathrm{Pim}-1$, a mouse gene implicated in leukemogenesis, to the pter-q12 region of chromosome 6 . Hum Genet 72: 262-265.

37. Dhanasekaran SM, Barrette TR, Ghosh D, Shah R, Varambally S, et al. (2001) Delineation of prognostic biomarkers in prostate cancer. Nature 412: 822-826.

38. Guo S, Mao X, Chen J, Huang B, Jin C, et al. (2010) Overexpression of Pim-1 in bladder cancer. J Exp Clin Cancer Res 29: 161.

39. Kim J, Roh M, Abdulkadir SA (2010) Pim1 promotes human prostate cancer cell tumorigenicity and c-MYC transcriptional activity. BMC Cancer 10: 248.

40. Reiser-Erkan C, Erkan M, Pan Z, Bekasi S, Giese NA, et al. (2008) Hypoxiainducible proto-oncogene $\mathrm{Pim}-1$ is a prognostic marker in pancreatic ductal adenocarcinoma. Cancer Biol Ther 7: 1352-1359.

41. Shah N, Pang B, Yeoh KG, Thorn S, Chen CS, et al. (2008) Potential roles for the PIM1 kinase in human cancer - a molecular and therapeutic appraisal. Eur J Cancer 44: 2144-2151.

42. Bachmann M, Möröy T (2005) The serine/threonine kinase Pim-1. Int J Biochem Cell Biol 37: 726-730.

43. Nga ME, Swe NN, Chen KT, Shen L, Lilly MB, et al. (2010) PIM-1 kinase expression in adipocytic neoplasms: diagnostic and biological implications. Int J Exp Pathol 91: 34-43.

44. Dai H, Li R, Wheeler T, Diaz de Vivar A, Frolov A, et al. (2005) Pim-2 upregulation: biological implications associated with disease progression and perinueral invasion in prostate cancer. Prostate 65: 276-286.

45. Epstein JI, Amin MB, Reuter VR, Mostofi FK (1998) The World Health Organization/International Society of Urological Pathology consensus classification of urothelial (transitional cell) neoplasms of the urinary bladder Bladder Consensus Conference Committee. Am J Surg Pathol 22: 1435-1448.

46. Edwards BK, Ward E, Kohler BA, Eheman C, Zauber AG, et al. (2010) Annual report to the nation on the status of cancer, 1975-2006, featuring colorectal cancer trends and impact of interventions (risk factors, screening, and treatment) to reduce future rates. Cancer 116: 544-573.

47. Jemal A, Siegel R, Xu J, Ward E (2010) Cancer statistics, 2010. CA Cancer J Clin 60: 277-300.

48. Narlik-Grassow M, Blanco-Aparicio C, Cecilia Y, Perez M, Muñoz-Galvan S, et al. (2013) Conditional transgenic expression of PIM1 kinase in prostate induces inflammation-dependent neoplasia. PLoS One 8: e60277. 
Citation: Grassow MN, Aparicio CB, Cecilia Y, Perez M, Galvan SM, et al. (2014) Pim1 Kinase Cooperates with Hormone Treatment to Promote Bladder and Ureteral Urothelial Hyperplasia. J Carcinog Mutagen 5: 161. doi:10.4172/2157-2518.1000161

Page 9 of 9

49. Lesche R, Groszer M, Gao J, Wang Y, Messing A, et al. (2002) Cre/loxPmediated inactivation of the murine Pten tumor suppressor gene. Genesis 32 148-149.

50. Zhang Y, Wang Z, Magnuson NS (2007) Pim-1 kinase-dependent phosphorylation of $\mathrm{p} 21 \mathrm{Cip} 1 / \mathrm{WAF} 1$ regulates its stability and cellular localization in H1299 cells. Mol Cancer Res 5: 909-922.

51. Wang Z, Zhang Y, Gu JJ, Davitt C, Reeves R, et al. (2010) Pim-2 phosphorylation of p21(Cip1/WAF1) enhances its stability and inhibits cell proliferation in HCT116 cells. Int J Biochem Cell Biol 42: 1030-1038.

52. Kurokawa K, Suzuki K, Okazaki H, Ito K, Shiono A, et al. (2002) Usefulness of PSA screening in outpatients with bladder cancer: preliminary results. Int $J$ Urol 9: 237-240.

53. Chen YC, Page JH, Chen R, Giovannucci E (2008) Family history of prostate and breast cancer and the risk of prostate cancer in the PSA era. Prostate 68: 1582-1591.

54. Takahashi T, Hoshi S, Satoh M, Kaneda T, Suzuki KI, et al. (1999) The study of PSA gene expression on urogenital cell lines. Int J Urol 6: 526-531.

55. Puzio-Kuter AM, Castillo-Martin M, Kinkade CW, Wang X, Shen TH, et al. (2009) Inactivation of p53 and Pten promotes invasive bladder cancer. Genes Dev 23: $675-680$

56. Seager C, Puzio-Kuter AM, Cordon-Cardo C, McKiernan J, Abate-Shen C (2010) Mouse models of human bladder cancer as a tool for drug discovery. Curr Protoc Pharmacol Chapter 14: Unit14.

57. Freeman KW, Welm BE, Gangula RD, Rosen JM, Ittmann M, et al. (2003)
Inducible prostate intraepithelial neoplasia with reversible hyperplasia in conditional FGFR1-expressing mice. Cancer Res 63: 8256-8263.

58. Li Z, Szabolcs M, Terwilliger JD, Efstratiadis A (2006) Prostatic intraepithelia neoplasia and adenocarcinoma in mice expressing a probasin-Neu oncogenic transgene. Carcinogenesis 27: 1054-1067.

59. Scherl A, Li JF, Cardiff RD, Schreiber-Agus N (2004) Prostatic intraepithelia neoplasia and intestinal metaplasia in prostates of probasin-RAS transgenic mice. Prostate 59: 448-459.

60. Valkenburg KC, Williams BO (2011) Mouse models of prostate cancer. Prostate Cancer 2011: 895238.

61. Wu Y, Wang YY, Nakamoto Y, Li YY, Baba T, et al. (2010) Accelerated hepatocellular carcinoma development in mice expressing the Pim-3 transgene selectively in the liver. Oncogene 29: 2228-2237.

62. Renner O, Blanco-Aparicio C, Grassow M, Cañamero M, Leal JF, et al (2008) Activation of phosphatidylinositol 3-kinase by membrane localization of p110alpha predisposes mammary glands to neoplastic transformation. Cancer Res 68: 9643-9653.

63. Renner O, Fominaya J, Alonso S, Blanco-Aparicio C, Leal JF, et al. (2007) Mst1, RanBP2 and elF4G are new markers for in vivo PI3K activation in murine and human prostate. Carcinogenesis 28: 1418-1425

64. Nicholson TM, Ricke EA, Marker PC, Miano JM, Mayer RD, et al. (2012) Testosterone and 17ß-estradiol induce glandular prostatic growth, bladder outlet obstruction, and voiding dysfunction in male mice. Endocrinology 153: 5556-5565. 